\title{
Mechanisms of $\alpha$-Synuclein Pathology and Treatment in the Enteric Nervous System
}

\author{
Charles M Lepkowsky ${ }^{1^{*}}$ \\ ${ }^{1}$ Independent Practice, 1143 Deer Trail Lane, Solvang, California, USA
}

Received: November 08, 2017; Accepted: November 21, 2017; Published: November 24, 2017

*Corresponding author: Charles M Lepkowsky, Independent Practice, 1143 Deer Trail Lane, Solvang, California 93463, USA, Tel: 805-688-1229; Fax: 805-686-9382; E-mail: clepkowsky@gmail.com

\begin{abstract}
$\alpha$-synuclein (Lewy Body) pathology is commonly found in the enteric nervous system (ENS) of patients diagnosed with Neurocognitive Disorder with Lewy Bodies (NCDLB) and Parkinson's Disease (PD). Lewy pathology in the ENS can produce symptoms of bowel immotility, including constipation, obstipation, and bowel impaction. These symptoms significantly reduce the quality of life for the patient, producing hardship for the patient and care providers. In Lewy body patients, medical intervention using acetylcholinesterase inhibitors (AChEIs) can significantly reduce or alleviate bowel immotility. The specific mechanism through which the cholinergic agonist Donepezil mitigates Lewy Body bowel immotility is explained.
\end{abstract}

Keywords:Neurocognitive Disorder with Lewy Bodies; Parkinson's Disease; Constipation; Donepezil; AChEI;

\section{Introduction}

The purpose of this paper is to explain the biochemical mechanisms responsible for the symptom of constipation in patients diagnosed with Parkinson's Disease (PD) and Neurocognitive Disorder with Lewy Bodies (NCDLB) patients, and the mechanisms through which Donepezil produces symptom relief.

\section{Cholinergic Lewy Pathology in the ENS}

Pathological $\alpha$-synuclein proteins called Lewy bodies have long been known to aggregatein the enteric nervous system (ENS) of patients diagnosed with PD and NCDLB [1-13]. Specifically, in PD and NCDLB, Lewy bodies appear in the myenteric plexus (MP) and the colonic submucosal plexus (CSMP) [8,14-20]. 95\% of MP innervation is cholinergic and the CSMP is innervated by the MP [21].

Similarly, cholinergic neural deficits and functional impairment have long been recognized as symptomatic features of PD and NCDLB [22-28]. Increasingly, cholinergic impairments in PD and NCDLB are attributed to Lewy Body pathology (Cholinergic impairment does not appear to be a consistent finding in Alzheimer's disease (AD) [27,42]. Research consistently demonstrates that autonomic dysfunction is a feature of PD and NCDLB, but not AD and that $\alpha$-synuclein expression is increased in NCDLB and PD, but not in AD [2,7,9,43-46]. For this reason, $\mathrm{AD}$ is not included in this discussion) $[23,28,29]$. The presence of $\alpha$-synuclein aggregates in the MP predates cognitive and motor functional manifestations of Lewy body diseases so consistently that it has been nominated as a potential biomarker for Lewy pathology $[10,17,30]$.

\section{Symptomatic Manifestations of Cholinergic Lewy Pathology in the ENS}

Lewy body cholinergic impairment in the ENS manifests symptomatically as gastric immotility and constipation $[13,31$ 41]. Increased colonic transit time and impaired gastric emptying are frequently found in PD patients [35,42]. The prevalence of constipation in $\mathrm{PD}$ is at least three times that of the general population, leading some researchersto suggest that constipation might be a universal feature of PD $[47,48]$. Bowel immotility can occur 20 years before diagnosis of PD or NCDLB, suggesting that it might be a prodromal symptom for both disorders [5,19,36,44,49-52].

As $\alpha$-synuclein pathology advances in the ENS, symptoms of gastric immotility advance from constipation to obstipation and impaction. Escalating gastric immotility in PD and NCDLB can interfere with mobility, sleep, cognition, and mood, increasing the cost of care, and potentially debilitating and/or dramatically reducing the quality of life for patients. [4, 34, 36, 53-56]

\section{Potential Exacerbation of ENS Symptoms by Anti- Parkinson Medication}

LPD and NCDLB patients with significant Parkinsonian motoric/gait features are often prescribed L-dopa agents like Carbidopa-Levodopa (known also by the brand names Sinemet and Stalevo) in order to preserve gait, balance, and other basic motor functions [40,57,58]. Carbidopa-Levodopa's potential side effects include constipation [59]. which can complicate or exacerbate gastric immotility due to ENS Lewy pathology. Medications frequently used for the treatment of resting tremor in PD and NCDLB includeTrihexyphenidyl (marketed as Artane or Trihex) and Benztropinemesylate (marketed as Cogentin), identified as definite anticholinergics that can also exacerbate gastric immotility through suppression of the cholinergic neurotransmitter pathways innervating the ENS [58, 60-62]. 


\section{Symptom Treatment of Cholinergic Lewy Pathology}

Because Lewy pathology produces cholinergic impairment, a practical approach to symptomatic relief for PD and NCDLB patients is the use of a cholinergic agonist, such as an acetylcholinesterase inhibitor(AChEI), to boost cholinergic activity [29,33,63-65]. AChEIs include Tacrine, Galantamine, Rivastigmine, and Donepezil. Low doses of Tacrine and Galantamine have reduced motor symptoms in PD patients $[22,66]$. Rivastigmine has been shown to reduce neuropsychiatric symptoms and improve cognitive function as measured by the Mini-Mental State Exam (MMSE) in patients with NCDLB [67-71]. However, in PD patients, improvements in cognition with Rivastigmine have also been associated with higher rates of nausea, vomiting, and tremor (Rare, potentially dangerous side effects of cholinergic agonists include rhabdomyolysis and neuroleptic malignant syndrome (NMS) [80-86].) [72].

Compared with other AChEIs, including Galantamine and Rivastigmine, the cholinergic agonist Donepezil has performed favorably for treating cognitive impairment in patients with PD and NCDLB, improving cognition, but with fewer side effects $[73,74]$. Donepezil has been shown to produce significant improvements in cognition and behavior which disappeared when Donepezil was withdrawn, but treatment gains were restored on recommencement of Donepezil [75]. Donepezil has been shown to improve cognition for up to 52 weeks in longterm treatment of NCDLB patients, without increasing the risk of Parkinsonian features or other clinically significant safety events $[76,77]$.

Donepezil has also been shown to reduce Lewy pathology cholinergic impairment including hallucinations and delusions and psychotic symptoms in PD patients, without apparent side effects or exacerbation of Parkinsonian symptoms [78-79]. Although an early study suggested that treatment of NCDLB with Donepezil was sometimes associated with an increase in Parkinsonian features, a Cochrane database systematic review of previous research using cholinergic agonists to treat PD \& NCDLB found that Donepezil produced consistent reduction in neurocognitive symptoms without exacerbation of Parkinsonian features or other side effects $[87,88]$. These findings have been reproduced in subsequent research $[89,90]$.

More specific to ENS Lewy pathology and impairment, Donepezil has been shown to reduce ANS symptoms including constipation in nongeriatric affective patients, and increase cholinergically mediated bowel contractions as much as $477 \%$ in patients suffering from severe intestinal dysmotility $[91,92]$.

\section{Symptom Treatment of Cholinergic Lewy Pathology in the ENS}

Despite its prevalence in Lewy Body patients [46, 47] and debilitating impact on quality of life, gastric immotility is rarely a focus of treatment for patients with PD and NCDLB [4,34,36,39,5356]. When PD and NCDLB constipation is addressed, primary care physicians typically recommend conventional (often over- the-counter) treatments, despite data demonstrating that such treatments are ineffective with this population [54].

Based on researchdemonstrating Donepezil's efficacy in treating cholinergic impairment in patients with PD and NCDLB, and its effectiveness in reducing constipation and increasing bowel motility in non geriatric patients [73-79,88-90,93,94]. Donepezil has been used specifically to treatconstipation in PD and NCDLB patients, with consequent significant reduction of the symptom of constipation, without exacerbation or instigation of other symptoms [39]. A follow up study indicated that the progression of Lewy body pathology had advanced in some patients, leading to exacerbation of CNS and ANS symptoms including blunted affect, dysphoric mood, generalized anxiety, sleep disturbance (onset, median and terminal waking, REM sleep behavior disorder or RSBD and/or REM sleep without atonia, or RSWA), cognitive interference (short-term memory loss and difficulty with wordfinding), passive suicidal ideation, appetite suppression, and exacerbation of Parkinsonian features (motor retardation, joint and muscle pain, reduced range of motion, diminished strength and coordination, increased tremor, gait disturbances, and difficulties with balance). However, there was no exacerbation of the symptom of constipation, nor emergence of new symptoms in any of the patients in the study, suggesting that Donepezil might have long-term benefit for mitigating cholinergic Lewy pathology in the ENS of patients with PD and NCDLB [40].

\section{The Mechanism of Symptom Relief for Cholinergic Lewy Pathology in the ENS}

The observed benefit of using Donepezil to reduce the symptom of constipation in PD and NCDLB patients bears some explanation. Specifically, what are the biochemical mechanisms responsible for the symptom of constipation, and through what mechanisms does Donepezil induce symptom relief?

Because 95\% of Myenteric Plexus (MP) innervation is cholinergic, Lewy Body pathology in the MP manifests primarily as $\alpha$-synuclein protein aggregation in the cholinergic neurons of the MP and the CSMP [8,14-21]. In the MP and CSMP, $\alpha$ synuclein pathology does not appear exclusively in the form of large Lewy bodies near the nucleus. Small Lewy bodies and other proteins aggregate even more abundantly in neurites (axons and dendrites) [33].

The specific biochemical mechanisms posited for $\alpha$-synuclein pathology-based reduction of cholinergic functioning include endoplasmic reticulum (ER) stress, blockage in endoplasmic reticulum (ER)-to-Golgi vesicular trafficking, and mitochondrial dysfunction, all of which contribute to $\alpha$-synuclein-induced cell death $[93,94]$. The degeneration of cholinergic neurons leads to a decline in the level of acetylcholine (ACh) [95].

The mechanisms through which Donepezil mitigates these symptoms is twofold. AChEIs like Donepezil inhibit the action of the ACh-hydrolyzing enzyme acetylcholinesterase (AChE), increasing ACh levels, with consequent reduction in symptoms associated with progressive cholinergic dysfunction [95]. Donepezil is a specific, reversible AChEinhibitor [96,97]. 
Donepezil also interacts independently with neuronal nicotinic ACh receptors [98]. Donepezil's dual action has made it a longstanding choice for countering cholinergic impairment $[74,95,98]$.

Donepezil's successful employment in the treatment of constipation in case studies of patients with PD and NCDLB, as well as its demonstrated efficacy in reducing constipation in PD and NCDLB patients using Carbidopa-Levodopa, suggests that the mechanism of boostingACh levels in the MP and CSMP restores motility to the bowel, significantly reducing constipation without increasing Parkinsonian features or other clinically significant symptoms $[39,40]$.

\section{Discussion and Conclusions}

As with the use of any medication, Donepezil's potential for symptom reduction has to be weighed against its potential side effects. These can include diarrhea, loss of appetite, muscle cramps, nausea, trouble in sleeping, unusual tiredness or weakness, and vomiting, with less common side effects including abnormal dreams, constipation, dizziness, drowsiness, fainting, frequent urination, headache, joint pain, stiffness, or swelling, mental depression, pain, unusual bleeding or bruising, and weight loss (Pfizer US Pharmaceuticals, 2016). AChEIs including Donepezil also have the potential for rare but potentially dangerous side effects, including muscle breakdown (rhabdomyolysis) and a neurological disorder called neuroleptic malignant syndrome (NMS) [80-86].

Donepezil has demonstrated efficacy in mitigating Lewy body impairment of the cholinergic pathways in the MP and CSMP of patients diagnosed with PD and NCDLB, increasing bowel motility and reducing the symptom of constipation, without exacerbating or instigating other symptoms $[39,40]$. One possible conclusion is that the use of the AChEI Donepezil compensates at least in part for Lewy body impairment of cholinergic pathways in the MP and CSMP, reducing the symptom of constipation in patients with PD and NCDLB.

In case studies, the use of Donepezilwas also associated with significant reductions in constipation and the resumption of daily bowel movements in patients using Carbidopa-Levodopa. Another possible conclusion is that Donepezil mitigates constipation in Lewy body patients receiving prescriptive Carbidopa-Levodopa.

The strength of these conclusions is limited by our current understanding of Lewy pathology, its etiology, and progression. Although these early findings suggest that Donepezil might be effective in reducing constipation in patients with PD and NCDLB through a mechanism that directly addresses Lewy body cholinergic impairment in the MP and CSMP, further research is necessary using larger numbers of subjects matched for diagnosis, age, gender, and other variables.

\section{References}

1. Kupsky W, Grimes M, Sweeting J, Bertsch R, Cote L. Parkinson's diseaseand megacolon. Neurology. 1987;37(7):1253. doi:10.1212/ WNL.37.7.1253
2. Shankle W, Landing B, Ang S, Chui H, Villarreal-Engelhardt G, Zarow C. Studies of the enteric nervous system in Alzheimer disease and other dementias of the elderly: enteric neurons in Alzheimer disease. Mod Pathol. 1993;6(1):10-14.

3. Braak H, Braak E. Pathoanatomy of Parkinson's disease. J Neurol. 2000;247:ii3-ii10. doi:10.1007/PL00007758

4. Chaudhuri K, Healy D, Schapira A. Non-motor symptoms of Parkinson'sdisease: diagnosisand management. Lancet Neurol. 2006;5(3):235-245. doi:10.1016/S1474-4422(06)70373-8

5. Abbott R, Webster R, Petrovitch H, Tanner C, Davis D, Masaki K, et al. Bowel movement frequency in late-life and incidental Lewy bodies. MovDisord. 2007;2(11):1581-1586. doi:10.1002/mds.21560

6. Lebouvier T, Chaumette T, Paillusson S, Duyckaerts C, Varannes BDS, Neunlist M, et al. The second brain and Parkinson's disease. Eur J Neurosci. 2009;30(5):735-741. doi:10.1111/j.14609568.2009.06873.x

7. Beach T, Adler C, Sue L, Vedders L, Lue L, White C, et al. Multiorgan distribution of phosphorylated $\alpha$-synuclein histopathology in subjects with Lewy body disorders. ActaNeuropathol. 2010;119(6):689-702. doi:10.1007/s00401-010-0664-3

8. Lebouvier T, Neunlist M, Varannes BDS, Coron E, Drouard A, $N^{\prime}$ Guyen J, et al. Colonic biopsies to assess the neuropathology of Parkinson's Disease and its relationship with symptoms. PLoS ONE. 2010;5(9):e12728. doi:10.1371/journal.pone.0012728

9. Gold A, Turkalp ZT, Munoz DG. Enteric alpha-synuclein expression is increased in Parkinson's disease but not Alzheimer's disease. MovDisord. 2013;28(2):237-241. doi:10.1002/mds.25298

10. SemarS, Klotz M, Letiembre M, Van Ginneken C, Braun A, Jost V, et al. Changes of the enteric nervous system in amyloid- $\beta$ protein precursor transgenic mice correlate with disease progression. J Alzheimers Dis. 2013;36(1):7-20. doi:10.3233/JAD-120511

11. Gelpi E, Navarro-Otano J, Tolosa E, Gaig C, Compta Y, Rey M, et al. Multiple organ involvement by alpha-synuclein pathology in Lewy body disorders. MovDisord. 2014;29(8):1010-1018. doi:10.1002/ mds. 25776

12. Cersosimo MG. Gastrointestinal Biopsies for the Diagnosis of AlphaSynuclein Pathology in Parkinson's disease. Gastroenterology Research and Practice. 2015;476041. Doi:10.1155/2015/476041

13. Corbillé $A G$, Neunlist $M$, Derkinderen, P. Cross-linking for the analysis of $\alpha$-synuclein in the enteric nervous system. J Neurochem. 2016;139(5):839-847. doi:10.1111/jnc.13845

14. Wakabayashi K, Takahashi H, Takeda S, Ohama E, Ikuta F. Lewy Bodies in the Enteric Nervous System in Parkinson's Disease. Arch HistolCytol. 1989;52:191-194.

15. Braaka H, De Vosb RAI, Bohlc J, Tredici KD. Gastric $\alpha$-synuclein immunoreactive inclusions in Meissner's and Auerbach's plexuses in cases staged for Parkinson's disease-related brain pathology. Neurosci Lett. 2006;396(1):67-72. doi:10.1016/j. neulet.2005.11.012

16. Hawkes $\mathrm{CH}$, Del Tredici K, Braak H. Parkinson's disease: a dualhit hypothesis. Neuropathol Appl Neurobiol. 2007;33(6):599614.

17. Minguez-Castellanos A, Chamorro CE, Escamilla-Sevilla F, OrtegaMoreno A, Rebollo A, Gomez-Rio M, et al. Do $\alpha$-synuclein aggregates 
in autonomic plexuses predate Lewy body disorders? a cohort study. Neurology. 2007;68(23):2012-2018. doi:10.1212/01.wnl. 0000264429.59379.d9

18. Holmqvist S, Chutna O, Bousset L, Aldrin-Kirk P, Li W, Björklund $\mathrm{T}$, et al. Direct evidence of Parkinson pathology spread from the gastrointestinal tract to the brain in rats. Acta Neurol Scand. 2014;128(6):805-820. doi:10.1007/s00401-014-1343-6

19. Iranzo A, Gelpi E, Tolosa E, Molinuevo J, Serradell M, Gaig C, et al. Neuropathology of prodromal Lewy body disease. MovDisord. 2014;29(3):410-415. doi:10.1002/mds.25825

20. Gjerløff T, Fedorova T, Knudsen K, Munk O, Nahimi A, Jacobsen $\mathrm{S}$, et al. Imaging acetylcholinesterase density in peripheral organs in Parkinson's disease with 11C-donepezil PET. Brain. 2015;138(3):653-663. doi:10.1093/brain/awu369

21. Porter AJ, Wattchow DA, Brookes SJH, Costa M. Cholinergic and nitrergicinterneurones in the myenteric plexus of the human colon. Gut. 2002;51(1):70-75.

22. Hutchinson M, Fazzini E. Cholinesterase inhibition in Parkinson's disease. J NeurolNeurosurg Psychiatry. 1996;61(3):324-325.

23. Tiraboschi P, Hansen L, Alford M, Sabbagh M, Schoos B, Masliah E, et al. Cholinergic dysfunction in diseases with Lewy bodies. Neurology. 2000;54(2):407-411.

24. Francis PT, Perry EK. Cholinergic and other neurotransmitter mechanisms in Parkinson's disease, Parkinson's disease dementia, and dementia with Lewy bodies. MovDisord. 2007;22(S17):S351-S357. doi:10.1002/mds.21683

25. Bohnen NI, Albin RL. The Cholinergic System and Parkinson Disease. Behav Brain Res. 2011;221(2):564-573. doi:10.1016/j. bbr.2009.12.048

26. Müller ML, Bohnen NI. Cholinergic Dysfunction in Parkinson's Disease. Curr Neurol Neurosci Rep. 2013;13(9):377. doi:10.1007/ s11910-013-0377-9

27. Grothe MJ, Schuster C, Bauer F, Heinsen H, Prudlo J, Teipel S. Atrophy of the cholinergic basal forebrain in dementia with Lewy bodies and Alzheimer's disease dementia. J Neurol. 2014;261(10):1939-1948. doi:10.1007/s00415-014-7439-z

28. Hall H, Reyes S, Landeck N, Bye C, Leanza G, Double K, et al. Hippocampal Lewy pathology and cholinergic dysfunction are associated with dementia in Parkinson's disease. Brain. 2014;137(9):2493-2508. doi:10.1093/brain/awu193

29. Perez-LloretS, BarrantesFJ.Deficitsin cholinergic neurotransmission and their clinical correlates in Parkinson's disease. NPJParkinson's Disease. 2016;2:16001. doi:10.1038/npjparkd.2016.1

30. Lebouvier T, Tasselli M, Paillusson S, Pouclet H, Neunlist M, Derkinderen P. Biopsableneural tissues: Toward new biomarkers for Parkinson's Disease? Front Psychiatry. 2010;1:128. doi:10.3389/ fpsyt.2010.00128

31. Edwards LL, Quigley EM, Pfeiffer RF. Gastrointestinal dysfunction in Parkinson's disease: frequency and pathophysiology. Neurology. 1992;42(4):726-732. doi:10.1212/WNL.42.4.726

32. Johanson JF, Sonnenberg A, Koch TR, McCarty D. Association of constipation with neurologic diseases. Dig Dis Sci. 1992;37(2):179186.

33. McKeith IG, Galasko D, Kosaka K, Perry E, Dickson D, Hansen L, et al. Consensus guidelines for the clinical and pathologic diagnosis of dementia with Lewy bodies (DLB): report of the consortium on DLB international workshop. Neurology. 1996;47(5):1113-1124.

34. Klockgether T. Parkinson's disease: clinical aspects. Cell Tissue Res. 2004;318(1):115-120. doi:10.1007/s00441-004-0975-6

35. Tanaka Y, Kato T, Nishida H, Yamada M, Koumura A, Sakurai T. Is there a delayed gastric emptying of patients with early-stage, untreated Parkinson's disease? An analysis using the 13C-acetate breath test. J Neurol. 2011;258(3):421-426. doi:10.1007/s00415-010-5769-z

36. Rossi M, Merello M, Perez-Lloret S. Management of constipation in Parkinson's disease. Expert Opinion on Pharmacotherapy. 2014;16(4):547-557. doi:10.1517/14656566.2015.997211

37. Visanji N, Marras C. The relevance of pre-motor symptoms in Parkinson's disease. Expert Rev Neurother. 2015;15(10):12051217. doi:10.1586/14737175.2015.1083423

38. Lepkowsky CM. Neurocognitive disorder with Lewy bodies: evidence-based diagnosis and treatment. Practice Innovations. 2016;1(4):234-242. doi:10.1037/pri0000031

39. Lepkowsky CM. Donepezil for Lewy body constipation: Four case studies. Activitas Nervosa Superior. 2017;59(1):19-27. doi:10.1007/ s41470-017-0004-1

40. Lepkowsky CM. Donepezil for Lewy body constipation: A six month follow-up. Journal of Molecular and Genetic Medicine. 2017;11(3), doi:10.4172/1747-0862.1000287

41. Sveinbjornsdottir S. The clinical symptoms of Parkinson's disease. J Neurochem. 2016;139(S1):318-324.

42. Jost WH, Schimrigk K. Constipation in Parkinson's disease. KlinischeWochenschrift. 1991;69(20):906-909.

43. Tiraboschi P, Hansen L, Alford M, Merdes A, Masliah E, Thal L, et al. Early and widespread cholinergic losses differentiate dementia with Lewy bodies from Alzheimer disease. Arch Gen Psychiatry. 2002;59(10):946-951.

44. Allan L, Ballard C, Allen J, Murray A, Davidson A, McKeith I, et al. Autonomic dysfunction in dementia. J Neurol Neurosurg Psychiatry. 2007;78(7):671-677. doi:10.1136/jnnp.2006.102343

45. ScharreD, Chang S, NagarajaH, Park A, AdeliA, Agrawal P, et al. Paired Studies Comparing ClinicalProfiles of Lewy Body Dementia with Alzheimer's and Parkinson's Diseases. J Alzheimers Dis. 2016; 4;54(3):995-1004. doi:10.3233/JAD-160384

46. Watanabe H, Ieda T, Katayama T, Takeda A, Aiba I, Doyu M, et al. Cardiac (123)Imetaiodobenzylguanidine (MIBG) uptake in dementia with Lewy bodies: comparison with Alzheimer's disease. J Neurol Neuro surg Psychiatry. 2001;70(6):781-783. doi:10.1371/ journal.pone.0012728

47. Kaye J, Gage H, Kimber A, Storey L, Trend P. Excess burden ofConstipation in Parkinson's disease: a pilot study. Mov Disord. 2006;21(8):1270-1273. doi:10.1002/mds.20942

48. Martinez-Martin P, Schapira A, Stocchi F, Sethi K, Odin P, MacPhee G, et al. Prevalence of nonmotor symptoms in Parkinson's disease in an international setting; study using nonmotor symptoms questionnaire in 545 patients. Mov Disord. 2007;22(11):16231629. doi:10.1002/mds.21586

49. Pfeiffer R. Gastrointestinal dysfunction in Parkinson's disease. Lancet: Neurol. 2003;2(2):107-116. 
50. Savica R, Carlin J, Grossard B, Bower J, Ahlskog J, Maraganore D, et al. Medical records documentation of constipation preceding Parkinson disease: A case-control study. Neurology. 2009;73(21):1752-1758. doi:10.1212/WNL.0b013e3181c34af5

51. Donaghy P, McKeith I. The clinical characteristics of dementia with Lewybodies and a consideration of prodromal diagnosis. Alzheimers Res Ther. 2014;6(4):46. doi:10.1186/alzrt274

52. International Dementia with Lewy Bodies Conference 2015.

53. Gonera E, Van't Hof M, Berger H, van Weel C, Horstink M. Symptoms and duration of the prodromal phase in Parkinson's disease. Mov Disord. 1997;12(6):871-876. doi:10.1002/mds.870120607

54. Phillips C, Polakoff D, Maue S, Mauch R. Assessment of ConstipationManagement in Long-Term Care Patients. J Am Med Dir Assoc. 2001;2(4):149-154.

55. Winter Y, Campenhausen SV, Brozova H, Skoupa J, Reese J, Bötzel K, et al. Costs of Parkinson's disease in Eastern Europe: A Czech cohort study. Parkinsonism RelatDisord. 2010;16(1):51-56. doi:10.1016/j. parkreldis.2009.07.005

56. Wasner G, Deuschl G. Pains in Parkinson disease-many syndromes underoneumbrella. Nat Rev Neurol. 2012;8(5):284-294 doi:10.1038/nrneurol.2012.54

57. Molloy S, McKeith I, O'Brien J, Burn D. The role of levodopa in themanagement of dementia with Lewy bodies. J Neurol Neurosurg Psychiatry. 2005;76(9):1200-1203. doi:10.1136/jnnp.2004.052332

58. Lepkowsky CM. Medications Linked to Cognitive Impairment in OlderAdults. Practice Innovations. 2016;1(4):253-264. doi:10.1037/ pri0000033

59. Dupont Pharmaceuticals: Product Information: Sinemet CR (carbidopa-levodopa),Wilmington, DE, 2016

60. Boustani MA, Campbell NL, Munger S, Maidment I, Fox GC Impact ofanticholinergics on the aging brain: a review and practical application. Aging Health. 2008;4(3):311-320. doi:10.2217/1745509X.4.3.311

61. Campbell N, Boustani M, Limbil T, Ott C, Fox C, Maidment I, et al. The cognitive impact of anticholinergics: a clinical review. Clinical Interventions in Aging. 2009;4(1):225-233.

62. Cai X, Campbell N, Khan B, Callahan C, Boustani M. Longtermanticholinergic use and the aging brain. Alzheimers Dement. 2013;9(4):377-385. doi:10.1016/j.jalz.2012.02.005

63. Kosaka K, Oyanagi S, Matsushita M, Hori A. Presenile dementiawith Alzheimer-, Pick and Lewy-body changes. Acta Neuropathol. 1976;36(3):221-233.

64. Perry E, Smith C, Court J, Perry R. Cholinergic nicotinic and muscarinic receptors in dementia of Alzheimer, Parkinson and Lewy body types. J Neural Transm Park Dis Dement Sect. 1990; 2(3):149158.

65. McKeith I. Spectrum of Parkinson's disease, Parkinson's dementia, and Lewybody dementia. Neurol Clin. 2000;18(4):865-902.

66. Aarsland D, Hutchinson M, Larsen J. Cognitive, psychiatric and motor responsetogalantamine in Parkinson's disease with dementia. Int ] Geriatr Psychiatry. 2003;18(10):937-941. doi:10.1002/gps.949

67. Folstein M, Folstein S, McHugh P. Mini-mental state: A practical method forgrading the cognitive state of patients for the clinician. J Psychiatr Res. 1975;12(3):189-198.
68. McKeith I, Del Ser T, Spano P, Emre M, Wesnes K, Anand R, et al. Efficacy of rivastigmine in dementia with Lewy bodies: a randomised, double-blind, placebo-controlled international study. Lancet. 2000;356(9247):2031-2036. doi:10.1016/S01406736(00)03399-7

69. McKeith I, Grace J, Walker Z, Byrne E, Wilkinson D, Steven T, et al. Rivastigmine in the treatment of dementia with Lewy bodies: preliminary findings from an open trial. Int J Geriatr Psychiatry. 2000;15(5):387-392.

70. Grace J, Daniel S, Stevens T, Shankar K, Walker Z, Byrne E, et al. Long-term use of rivastigmine in patients with dementia with Lewy bodies: An open-label trial. Int Psychogeriatr. 2001;13(2):199-205. doi:10.1017/S104161020100758X

71. Bullock R, Cameron A. Rivastigmine for the Treatment of Dementia and VisualHallucinations Associated with Parkinson's Disease: A Case Series. Curr Med Res Opin. 2002;18(5):258-264.

72. Emre M, Aarsland D, Albanese A, Byrne J, Deuschl G, De Deyn P, et al. Rivastigmine for dementia associated with Parkinson's disease. N Engl J Med. 2004;351:2509-2518. doi:10.1056/NEJMoa041470

73. Bosboom J, Stoffers D, Wolters E. Cognitive dysfunction and dementia inParkinson's disease. J Neural Transm. 2004;111(10):1303-1315.

74. Birks J. Cholinesterase inhibitors for Alzheimer's disease. Cochrane Database Syst Rev. 2006;1:CD005593. doi:10.1002/14651858. CD005593

75. MinettT, Wilkinson L, Daniel S, Sanders J, Richardson J, Littlewood E, et al. What happens when donepezil is suddenly withdrawn? An open label trial in dementia with Lewy bodies and Parkinson's disease with dementia. Int J Geriatr Psychiatry. 2003;18(11):988993.

76. Mori E, Ikeda M, Kosaka K. Donepezil for dementia with Lewy bodies: a randomized, placebocontrolled trial. Ann Neurol. 2012;72(1):4152. doi:10.1002/ana.23557

77. Mori E, IkedaM, Nagai R, Matsuo K, NakagawaM, Kosaka K. Longtermdonepezil use for dementia with Lewy bodies: results from an open-label extension of Phase III trial. Alzheimers Res Ther. 2015;7(1):5. doi:10.1186/s13195-014-0081-2

78. Fabbrini G, Barbanti P, Aurilia C, Pauletti C, Lenzi G, Meco G. Donepezil in the treatment of hallucinations and delusions in Parkinson's disease. Ital J Neurol Sci. 2002; 23(1), 41-43. doi:10.1007/ s100720200022

79. Bergman J, Lerner V. Successful use of donepezil for the treatment of psychotic symptoms in patients with Parkinson's disease. Clin Neuropharmacol. 2002;25(2):107-110.

80. Bourke D. Possible association between donepezil and worsening Parkinson'sdisease. Ann Pharmacother. 1998;32(5): 610-611. doi:10.1345/aph.17355

81. Babic T, Zurak N. Convulsions induced by donepezil. J Neurol Neurosurg Psychiatry. 1999;66(3):410.

82. Hashimoto $M$, Imamura $T$, Tanimukai $S$, Kazui $H$, Mori E. Urinaryincontinence: an unrecognized adverse effect with donepezil. Lancet. 2000;356(9229):568. doi:10.1016/S01406736(00)02588-5

83. Onofrj M, Thomas A. Severe worsening of parkinsonism in Lewy bodydementia due to donepezil. Neurolog. 2003;61(10):1452. Doi:10.1212/01.WNL.0000094201.80888.DA 
84. Rozzini L, Ghianda D, Trabucchi M, Padovani A. Severe worsening ofparkinsonism in Lewy body dementia due to donepezil. Neurology. 2004;63(8):1543-1544. doi:10.1212/WNL.63.8.1543-a

85. Iraqi A, Hughes T. An unusual case of nightmares with galantamine. J AmGeriatr Soc. 2009;57(3):565. doi:10.1111/j.15325415.2009.02157.x

86. News Medical: Health News and Information: Alzheimer's drug Aricept (donepezil) linkedto serious side effects.

87. Shea C, MacKnight C, Rockwood K. Donepezil for treatment of dementia withLewy bodies: A case series of nine patients. IntPsychogeriatr. 1998;10(3):229-238.

88. Rolinski M, Fox C, Maidment I, McShane R. Cholinesterase inhibitors fordementia with Lewy bodies, Parkinson's disease dementia and cognitive impairment in Parkinson's disease. Cochrane Database Syst Rev. 2012; 3:CD006504. doi:10.1002/14651858.CD006504. pub2

89. Ikeda M, Mori E, Kosaka K, Iseki E, Hashimoto M, Matsukawa N, et al. Longterm safety and efficacy of donepezil in patients with dementia with Lewy bodies: results from a 52week, openlabel, multi-center extension study. Dement Geriatr Cogn Disord. 2013;36(3-4):229241. doi:10.1159/000351672

90. Ikeda M, Mori E, Matsuo K, Nakagawa M, Kosaka K. Donepezil for dementiawith Lewy bodies: a randomized, placebo-controlled, confirmatory phase III trial. Alzheimers Res Ther. 2015;7(1):4. doi:10.1186/s13195-014-0083-0

91. Jacobsen F, Comas-Díaz L. Donepezil for psychotropic-induced memory loss. J Clin Psychiatry. 1999;60(10):698-704.

92. Broad J, Kung V, Boundouki G, Aziz Q, De Maeyer J, Knowles C.
Cholinergic interactions between donepezil and prucalopride in human colon: potential to treat severe intestinal dysmotility. Br J Pharmacol. 2013;170(6):1253-1261. doi:10.1111/bph.12397

93. Smith WW, Jiang H, Pei Z, Tanaka Y, Morita H, Sawa A, et al. Endoplasmic reticulum stress and mitochondrial cell death pathways mediate A53T mutant alpha-synuclein-induced toxicity. Human Molecular Genetics. 2005;14(24):3801-3811. doi:10.1093/ hmg/ddi396

94. Cooper AA, Gitler AD, Cashikar A, Haynes CM, Hill KJ, BhullarB, et al. $\alpha$-Synuclein blocks ER-Golgi traffic and Rab1 rescues neuron loss in Parkinson's models. Science. 2006;313(5785):324-328. doi:10.1126/science.1129462

95. Parsons CG, Danysz W, Dekundy A, Pulte I. Memantine andcholinesterase inhibitors: Complementary mechanisms in the treatment of Alzheimer's disease. Neurotox Res. 2013;24(3):358369. doi:10.1007/s12640-013-9398-z

96. DavidssonP, Blennow K, Andreasen N, Eriksson B, Minthon L, Hesse C. Differential increase in cerebrospinal fluid-acetylcholinesterase after treatment with acetylcholinesterase inhibitors in patients with Alzheimer's disease. Neurosci Lett. 2001;300(3):157-160.

97. Wilkinson DG, Francis PT, SchwamE, Payne-Parrish J. Cholinesteraseinhibitorsused in the treatment of Alzheimer's disease: the relationship between pharmacological effects and clinical efficacy. Drugs Aging. 2004;21(7):453-478.

98. Di Angelantonio S, Bernardi G, Mercuri NB. Donepezil modulates nicotinicreceptors of substantia nigra dopaminergic neurons. British Journal of Pharmacology. 2004;141(4):644-652. doi:10.1038/ sj.bjp.0705660 